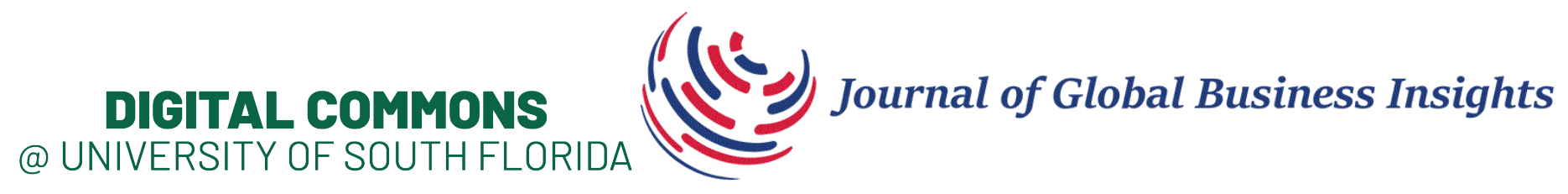

September 2018

\title{
Employee wellness innovations in hospitality workplaces: Learning from high-tech corporations
}

Tingting Zhang

University of Central Florida, tingting.zhang@ucf.edu

Follow this and additional works at: https://digitalcommons.usf.edu/globe

Part of the Business Administration, Management, and Operations Commons, and the Human Resources Management Commons

This Refereed Article is brought to you for free and open access by the M3 Center at the University of South Florida Sarasota-Manatee at Digital Commons @ University of South Florida. It has been accepted for inclusion in Journal of Global Business Insights by an authorized editor of Digital Commons @ University of South Florida. For more information, please contact digitalcommons@usf.edu.

\section{Recommended Citation}

Zhang, T. (2018). Employee wellness innovations in hospitality workplaces: Learning from high-tech corporations. Journal of Global Business Insights, 3(2), 52-66. https://www.doi.org/10.5038/ 2640-6489.3.2.1003

Revisions

Submission date: Aug. 12, 2018; 1st Revision: Sep. 16, 2018; 2nd Revision: Sep. 24, 2018; Acceptance: Sep. 25, 2018 


\title{
Employee Wellness Innovations in Hospitality Workplaces: Learning From High-Tech Corporations
}

\author{
Tingting Zhang
}

\author{
Rosen College of Hospitality Management \\ University of Central Florida, United States \\ tingting.zhang@ucf.edu
}

\begin{abstract}
Employee wellness programs are known to bring many benefits to companies. However, due to the unique hospitality job conditions and requirements, employee wellness programs usually suffer from low participation and engagement. This paper reviews various innovations of employee wellness programs in high-tech corporations as well as some hospitality enterprises that are well known for great places to work for. Based on the review findings, the paper suggests effective and plausible solutions to generate high participation and engagement with employee wellness programs in the hospitality workplaces. Limitations and future research directions are discussed in the end of the paper.
\end{abstract}

Keywords: high-tech companies, hospitality workplaces, employee wellness programs, high participation, Google, Apple

\section{Introduction}

In the past three decades, US employers have reported that budgets for healthcare costs have been at double-digit annual growth rates and incompatible with sustainable business strategies (Byrne et al., 2011). This steep rise in healthcare spending has changed the role of the employer from passively purchasing services for the treatment of disease to actively engaging in programs and benefit plan designs in attempts to control unnecessary healthcare expenses (Byrne et al., 2011). More specifically, employers have redirected their efforts at population health management and incorporating wellness and disease prevention programs to control healthcare costs. Wellness programs have become among the most commonly practiced business strategies (Byrne et al., 2011). However, with regards to wellness research, given that wellness is regarded as part of social marketing (Lefebvre \& Flora, 1988) to promote healthy behaviors such as physical exercise or healthy eating (Byrne et al., 2011) and to improve people's lives, scholars in social marketing have mainly focused on the studies of wellness from the perspective of social welfare (Mistry et al., 2012) and community campaigns (Kaplan \& Stone, 2013). There have been a limited number of studies that have examined this subject from the perspective of corporate gains and the provision of innovative wellness programs for better effects on employees.

High-tech companies such as Google, Apple, and Facebook are famous for employee benefits and wellness programs, which help make them attractive places to work. For example, at Google, 
employees are able to take showers, receive massages, and do laundry during their work time. Leisure facilities such as ping-pong tables, Lego stations, and nap pods are available in the office. Google employees enjoy unlimited healthy food provided by the company and receive incentives and bonuses if they choose a healthy lifestyle. Similar to Google (Oscar, 2014), other high-tech companies like Facebook, SAS, have been investing large sums to innovate and improve their employee wellness programs, which in turn accelerates work productivity and job satisfaction (Huddleston, 2014). As such, many high-tech corporations are known as Best Companies to Work For as listed by Health Fitness Revolution (2015).

On the other hand, hospitality enterprises including chain restaurants and hotels strive for excellency of service for their customers - a goal that is highly dependent on the performance of their employees. However, many studies have shown that hospitality and service employees work in constantly changing work environments, which poses tremendous challenges to their health and wellness. Therefore, employee wellness programs play an important role in improving an employees' job performance in hospitality workplaces (Xanthopoulou, Bakker, Demerouti, \& Schaufeli, 2009a; Xanthopoulou, Bakker, Demerouti, \& Schaufeli, 2009b). Additionally, the nature of hospitality jobs is different from that of the typical corporate work environment (Abdel-Moty, 2010). For instance, front desk clerks and food servers need to stand for nearly eight hours on their shifts. Housekeeping staff need to stay up late if they are assigned to a night shift. Hospitality workers' physical and psychological health can be affected by the shift work and long-time standing requirements, resulting in disrupted sleep patterns, stomach trouble, and mental stress (Stellman, 1999).

Research has shown that corporations have gained many benefits from implementing successful employee wellness programs, including enhanced employee engagement (Goetzel \& Ozminkowski, 2008). Engaged employees are able to provide a higher quality of service for customers, which in turn generates higher customer satisfaction and loyalty to the company. In addition, employee wellness programs can reduce healthcare expenditures for companies (Anderko et al., 2012). Although recognizing benefits from the provision of employee wellness programs - healthy and fit staff are able to handle stress better and become more productive in their work and more engaged with their companies - companies encounter challenges when they are developing their company's version of a wellness programs.

According to Borenstein (2015), many wellness programs suffer from low participation levels. Only 40 percent of employees who are aware of the wellness program say they actually participate in it (Boyle \& Harter, 2014). Limitations of time, a lack motivation to do fitness activities, and privacy (not wanting colleagues and senior managers around when doing exercise) are among the main factors for these low participation levels. Therefore, identifying effective and plausible employee wellness programs for hospitality enterprises could be a critical task to drive employee engagement and consequently improve overall service quality and better customer relationships. This paper aims to review the effective and successful wellness programs offered in high-tech corporations, compare them with existing programs in some well-known hospitality units, and ultimately to make suggestions for improvements and innovations to employee wellness programs for better participation and positive effect among the hospitality workforce. 


\section{Literature Review}

\section{Employee Wellness Programs}

Employee wellness programs, also called worksite wellness programs or corporate wellness programs, are programs developed by companies to promote and support the health, safety, and well-being of their staff (Pronk, 2014). The programs are designed to encourage healthier lifestyle behavior among their employees and reduce company healthcare spending in the long term (Pronk, 2014). Traditional wellness programs usually include health-promotion activities, health-risk assessments, biometric screenings, worksite clinical care, wellness interventions, and occupational health services. The wellness perks usually include health conferences and classes, walking competitions, and healthy snacks for meetings and breaks. The rewards to motivate employees can include healthy food or drinks, pedometers, and stress balls. According to the Gallup-Sharecare Well-Being Index (2015), employee programs should focus on these five aspects: purpose, social, financial, community, and physical (Boyle, \& Harter, 2014).

Table 1. Top Five Aspects of Job Satisfaction

\begin{tabular}{|c|c|c|c|c|c|c|c|c|c|c|c|}
\hline & $\begin{array}{c}2004 \\
(n=604)\end{array}$ & $\begin{array}{c}2005 \\
(\mathbf{n}=601)\end{array}$ & $\begin{array}{c}2006 \\
(\mathrm{n}=605)\end{array}$ & $\begin{array}{c}2007 \\
(\mathbf{n}=604)\end{array}$ & $\begin{array}{c}2008 \\
(\mathrm{n}=601)\end{array}$ & $\begin{array}{c}2009 \\
(\mathrm{n}=601)\end{array}$ & $\begin{array}{c}2010 \\
(\mathbf{n}=600)\end{array}$ & $\begin{array}{c}2011 \\
(\mathrm{n}=600)\end{array}$ & $\begin{array}{c}2012 \\
(\mathbf{n}=600)\end{array}$ & $\begin{array}{c}2013 \\
(n=600)\end{array}$ & $\begin{array}{c}2014 \\
(n=600)\end{array}$ \\
\hline $\begin{array}{l}\text { Respectful } \\
\text { treatment of all } \\
\text { employees at all } \\
\text { levels }\end{array}$ & - & - & - & - & - & - & - & - & - & - & $72 \%(1)$ \\
\hline $\begin{array}{l}\text { Trust between } \\
\text { employees and } \\
\text { senior } \\
\text { management }\end{array}$ & - & - & - & - & - & - & - & - & - & - & $64 \%(2)$ \\
\hline Benefits, overall & $68 \%(1)$ & $63 \%(1)$ & $65 \%(2)$ & $59 \%(1)$ & $57 \%(2)$ & $60 \%(2)$ & $60 \%(2)$ & $53 \%(5)$ & $53 \%$ & $53 \%(4)$ & $63 \%(3)$ \\
\hline Compensation/pay & $63 \%(2)$ & $61 \%(2)$ & $67 \%(1)$ & $59 \%(1)$ & $53 \%(3)$ & $57 \%(3)$ & $53 \%(5)$ & $54 \%(4)$ & $60 \%(3)$ & $60 \%(1)$ & $61 \%(4)$ \\
\hline Job security & $60 \%(4)$ & $59 \%(4)$ & $59 \%(3)$ & $53 \%(2)$ & $59 \%(1)$ & $63 \%(1)$ & $63 \%(1)$ & $63 \%(1)$ & $61 \%(2)$ & $59 \%(2)$ & $59 \%(5)$ \\
\hline
\end{tabular}

Note: a dash (-) indicates the question was not asked on that year's survey. Table represents the percentage of respondents who rated each aspect as very important to their job satisfaction. Percentages are based on a scale where $1=$ very unimportant and 4=very important.

Source: Employee Job Satisfaction and Engagement (Society for Human Resource Management [SHRM], 2015)

A study by Hochart and Lang (2011) showed that worksite wellness programs affected an employer's workplace culture and helped healthy employees stay at low risk of mental breakdown, while reducing risk levels for those at moderate or high risk. Another study (Harter, Schmidt, \& Keyes, 2003) showed that healthy and fit employees can control themselves better when they feel stressed and are more productive and engaged at work, which leads to higher productivity, higher sales, and higher profitability. Some scholars also stated that employee wellness can increase work engagement (Bakker, Schaufeli, Leiter, \& Taris, 2008). Since wellness programs can improve physical and mental health, they indirectly persuade employees to work harder (Xanthopoulou et al., 2009a; Xanthopoulou et al., 2009b). Also, a healthy working environment can promote innovation, and excellent social aspects of the workplace can have positive effects on workplace engagement (Hakanen, 2006). According to a survey report (SHRM, 2015) about employee satisfaction, employee benefits have been among the five most important factors for job satisfaction every year since 2002, with the exception of 2012 (Table 1). 


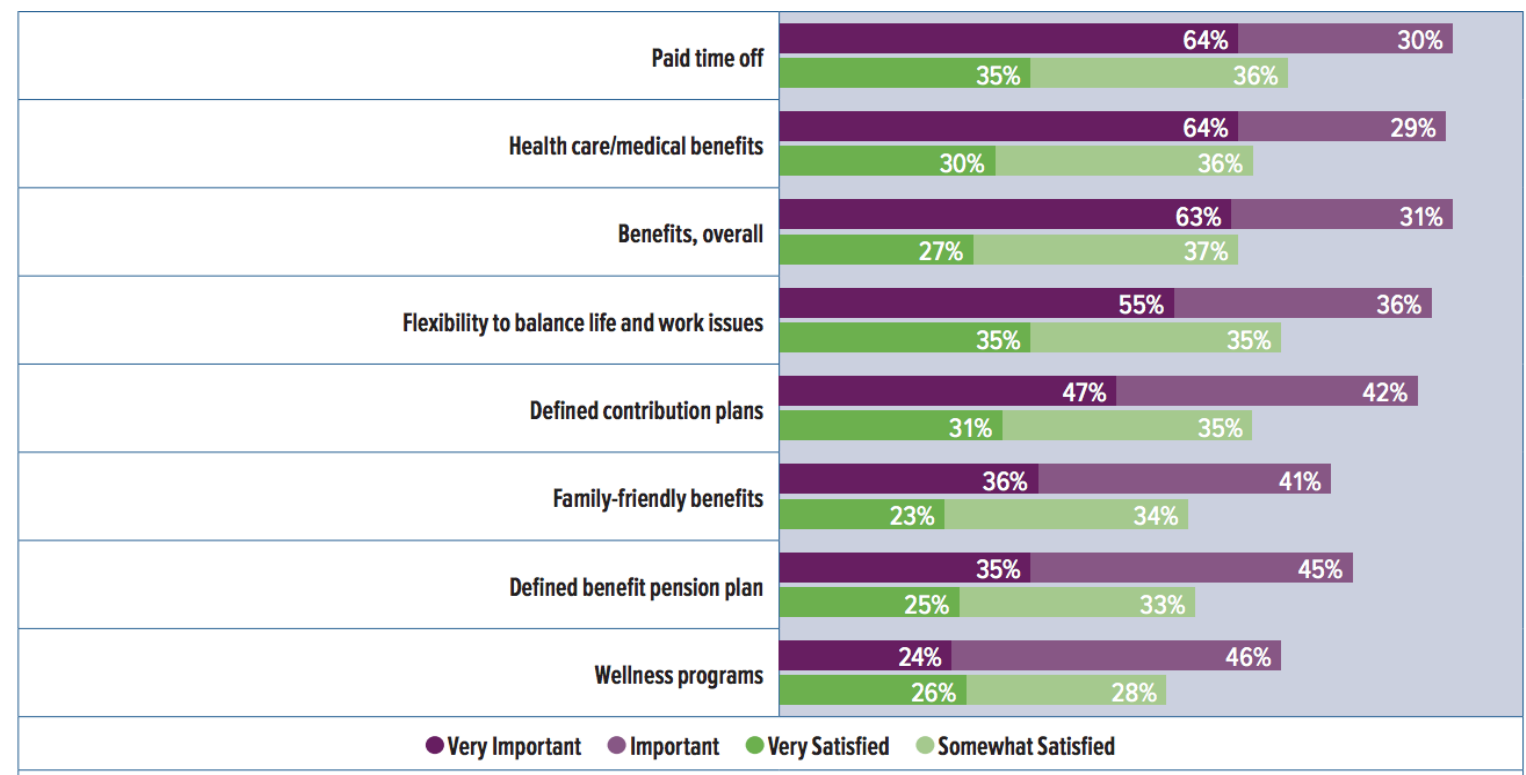

Note: $\mathrm{n}=600$. Importance percentages are based on a scale where $1=$ very unimportant and $4=$ very important. Satisfaction percentages are based on a scale were $1=$ very dissatisfied and $5=$ very satisfied. Data are sorted in descending order by the percentage of respondents who indicated very important.

Source: Employee Job Satisfaction and Engagement (SHRM, 2015)

Figure 1. Importance of and satisfaction with benefits aspects

Also, as Figure 1 shows (SHRM, 2015), though most organizations offered paid holidays, only 58 percent offered a paid time-off (PTO) plan. Moreover, many organizations did not offer family-friendly benefits. The report showed that only 28 percent of companies offered an on-site mother's room, 10 percent offered a child care referral service, and 1 percent offered geriatric counseling.

Engaged employees can transfer their happiness and positive emotions onto others (Bakker et al., 2008). When employees are highly engaged, they tend to perform very well with customers, who will report favorable employee performance. (Bakker et al., 2008). As a result, these positive relationships will lead to customer loyalty. A study by Line and Runyan (2012) examined the relationship between employee satisfaction and customer satisfaction in the hospitality industry, and how service operations are related to customer perceptions and behaviors. Their findings indicated that an engaged employee can make customers more satisfied and ultimately add financial profit to the company.

\section{Uniqueness of Hospitality Workplaces}

Hospitality industries are striving hard to achieve sustainability and success in a competitive market (Wang, Tsai, \& Tsai, 2014). It is important for hospitality organizations to do social good and to add that goodwill to the bottom line of their business (Lee \& Pati, 2012). Unlike employees at high-tech companies, studies have shown that hospitality and service employees work in constantly changing work environments. Employee wellness plays an important role in their work performance (Xanthopoulou et al., 2009a). Hospitality employees provide service to various customers from different backgrounds and engage in teamwork with colleagues and supervisors from different departments. Also, they may experience unpredictable obstacles and be required to maintain a positive attitude with customers. Most positions in hotels often involve 
repetitive work, awkward posture, and standing for a relatively long time (Ministry of Manpower, 2003). For instance, hotel front desk employees have to stand at the front desk and keep looking down at computers during their eight-hour shifts. Employees participating in shift work are required to work against their natural circadian rhythm (Blachowicz \& Letizia, 2006); as a result, their physiological and psychological health can be affected by such afflictions as disrupted sleep patterns, stomach trouble, and stress (Stellman, 1999), while at the same time they must provide service to guests efficiently, courteously, and accurately (Bureau of Labor Statistics, 2010).

\section{Methods}

The purpose of the current study was to uncover effective and innovative wellness programs for employees and to suggest appropriate innovations for employee wellness programs in hospitality enterprises. Due to the exploratory nature of the study, a qualitative approach was adopted. Business cases of employee wellness programs in mainstream high-tech companies and wellknown hospitality units are discussed and presented in this section. Fortune (2015) conducted a study among American companies titled Great Place to Work For. The survey contained questions related to employees' attitudes about their job satisfaction, pay, camaraderie with coworkers, their management's credibility, and their company's wellness programs (Fortune, 2015). According to the survey results, there were only five hospitality companies listed in the top 100 rankings. Most companies on the list were in the high-tech and insurance industries. In this section, I analyze the innovativeness of employee wellness programs from some high-tech companies and from well-known hospitality companies in the ranking.

\section{Innovative Wellness Programs in High-Tech Companies}

\section{Case 1: Google}

Google's wellness program is one that tries to build a happy and healthy work environment. Employees are treated with free snacks and coconut water. To encourage employees to eat healthy snacks, dried fruits and health bars are placed in transparent plastic or glass boxes, while candies and cookies are hidden in opaque jars. Another clever design is that the various foods in the cafeteria are colored with nutrition information. Food with a red label means that it is unhealthy, while healthy food such as lettuce salad has a green label. In addition, aside from the scooters and ping-pong tables we can see in many companies, Google lets its employees design their own standing desks (see Exhibit 1). According to Paul (2014), sitting too much can increase disability by 50 percent among people who are aged 60 and older, even if they go to the gym regularly. Standing desks make Google's employees feel more comfortable when they work: they find it much easier to brainstorm with their co-workers and they sit less in the office.

Google also organized a competition challenging its employees to cook healthy lunches. Moreover, employees have access to a free gym and can take free dance classes. Google also takes care of its employees' family members. If an employee dies, that employee's spouse can receive half the employee's salary for ten years. Anyone who joins Google is immediately eligible for this benefit. On top of the half-salary, the spouse will also receive company stock. If they have children, their children will be given $\$ 1,000$ per month until they are 19 years old. Gay couples can receive the same benefits. 


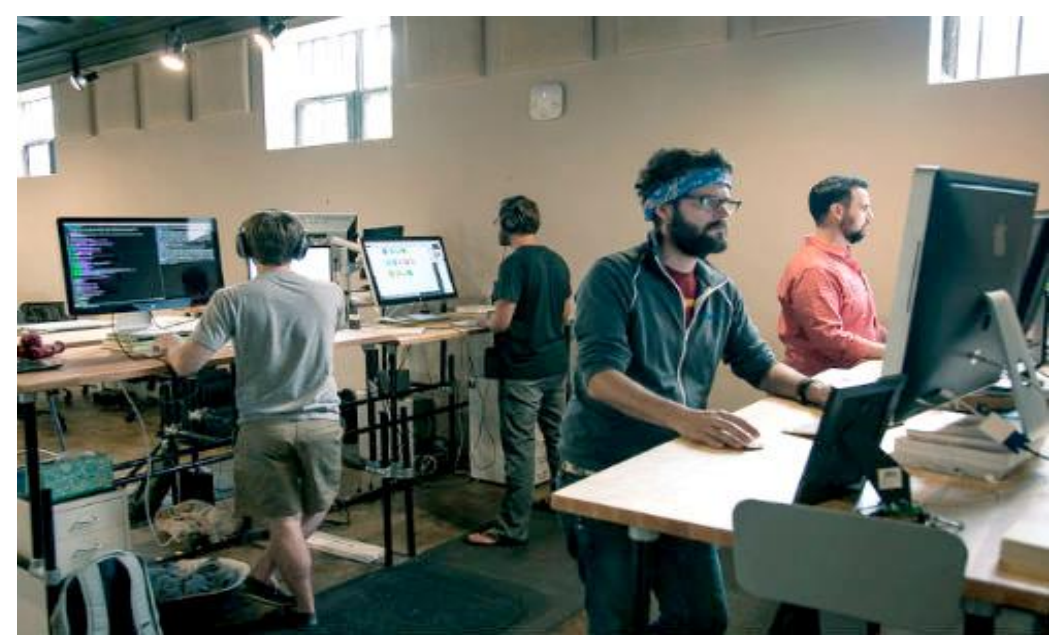

Exhibit 1. The Googlers are working on their standing desks.

\section{Case 2: Apple}

Part-time employees at Apple enjoy the same health benefits as full-time employees (Eadicicco, 2015). Managers developed a Design Plus Health kit for their employees. The kit contains weighted coffee mugs (see Exhibit 2), which work as dumbbells when the employees drink coffee or water. The kit also contains coasters (see Exhibit 3) with images of teeth so that employees can see the stains they might leave on their own teeth if they drink too much coffee or tea. There are healthy sticky notes in the kit to remind employees to eat healthily or exercise more (See Exhibit 4). Since most people live a busy and fast lifestyle now, they have little time to go to the gym. Apple gave Design + Health guidebooks to its program designers to teach them how to do some exercise in the office (see Exhibit 5).

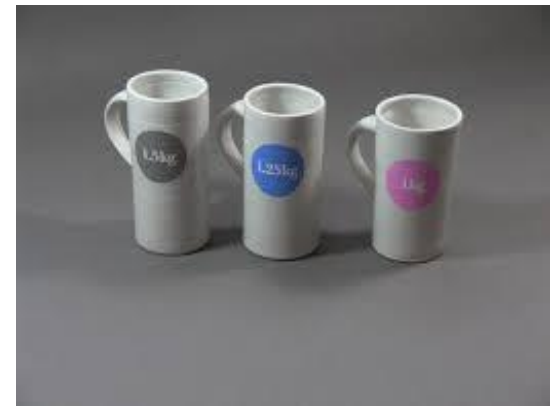

Exhibit 2. Coffee mugs

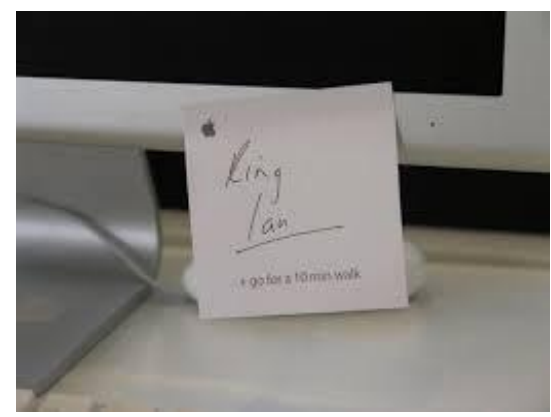

Exhibit 4. Healthy sticky notes

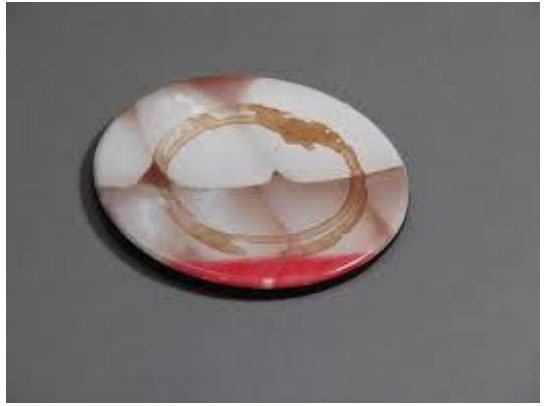

Exhibit 3. Coffee coasters

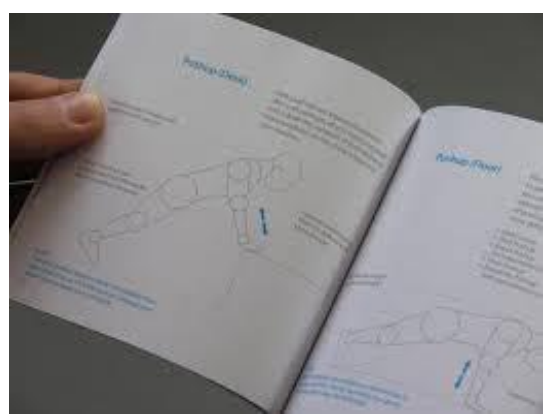

Exhibit 5. Design +Health guiding books 


\section{Case 3: Intel}

Intel started the Encore Fellowship Program for its aging employees in 2011 (Intel, 2015). To bridge the gap between the high-pressure working lifestyle and the more relaxing retirement lifestyle, Intel cooperated with non-profit organizations to provide its retired employees with opportunities to solve technical issues. The retirees can earn a $\$ 25,000$ stipend and health insurance coverage every year. This program is very useful for senior employees who have difficulty working regular hours but still want to live a meaningful life. Another of Intel's wellness initiatives is called Health for Life. (Intel, 2015) Through Health for Life, the company provides excellent medical and dental coverage and preventive care, as well as access to mental health and fitness resources. Employees can take part in personal development seminars to find effective means to balance life and work. The company also offers online homework assistance for the children of employees who are too busy to help with homework directly. Some Intel offices provide assistance finding quality child care and priority access to child care centers near the workplace. Programs also include access to summer camps, and tax deferral options for child care services. For employees who are worrying about taking care of their aging parents, the program offers on-site caregiver training.

\section{Case 4: Evernote}

Evernote is considered one of the coolest places to work (Garun, 2012). Evernote sends professional housekeeping staff to its employees' homes twice per month. This benefit allows busy and hardworking employees freedom from worrying about their home cleaning issues; they can be happier and concentrate on product development. In addition, employees have unlimited vacation allowance if they complete their work. Phil Libin, the CEO of Evernote, encourages his team to take a break from high pressure work by providing them with a $\$ 1,000$ travel fund annually (Garun, 2012). The company hopes that employees can work in a good mental state. All workers can see everybody (see Exhibit 6) around the office, which can be useful for having casual conversation with co-workers. Inter-office emails are discouraged because people cannot read the expression on each other's faces when they communicate through emails.

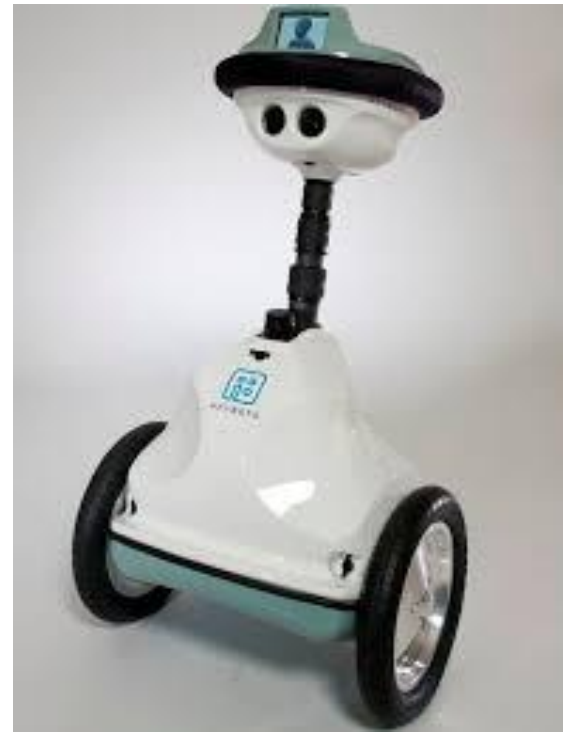

Exhibit 6. Anybots in Evernote office. 


\section{Case 5: Facebook}

Employees can take free dinner home. If they work too late, their family can come to eat with them at work. No one feels strange seeing children in the cafeteria. The company also provides each employee with $\$ 3,000$ for child care expenses and up to $\$ 5,000$ for adoption fees. Employees who have just had new babies can receive $\$ 4,000$. Facebook has also promised to pay for egg freezing fees for its female employees since 2014 (Rooney, 2014). After freezing their eggs, female employees can choose when to put an egg back into their womb. So, when they cannot get pregnant naturally, they can still have children. This service is extremely expensive: each egg freezing treatment costs $\$ 10,000$ with egg storage fees of $\$ 500$ per year. The maximum Facebook will reimburse is $\$ 20,000$ (Rooney, 2014). This benefit will help redefine the conventional gender-biased roles in the workplace-women can now focus on their careers as men traditionally have, instead of having to choose between a career and a family.

Besides the aforementioned cases about employee wellness programs, there are some other innovations in this respect. For example, employees at Airbnb are allowed to take their pets to work every day. They can have lunch with their pets and bring them to yoga classes, or even enjoy massages together. According to Messieh (2012)'s observation, unlike Casual Friday in most companies, Airbnb organizes Formal Friday to encourage its employees to dress up on Fridays. Dropbox offers daily breakfast, lunch, and dinner to its employees. The company tries to provide healthy food to its employees and save them from having to cook as well. Similar to Airbnb, Dropbox employees can have happy hours called Whisky Fridays. The workers can turn busy work into a party on these days. Unlike many other companies offering unlimited food, Yammer makes sure its employees maintain a healthy lifestyle with fitness classes on site and free bikes to use during the day. On Valentine's Day, workers can take free cupcakes. Zynga, as a provider of social video game services, provides the game designers with on-site gaming rooms. Gaming systems such as Nintendo, Xbox 360, and PS3, as well as traditional arcade games can be found in relaxing lounges (Messieh, 2012). Staff who has just broken up with their partners can take paid time off in Tokyo-based Hime \& Company. Managers understand that no one can be productive after a relationship has ended; two or three days off can help refresh employees in this situation. The company also gives staff paid time off to go shopping during onsales season. Thanks to this benefit, employees do not have to take half-days off to go to sales or feel guilty about taking their shopping bags into the office (Chisa, 2008).

\section{Successful Employee Wellness Programs in Some Hospitality Units}

According to the Great Place to Work For survey (Fortune, 2015), the following hospitality companies are good at creating employee benefits: Wegmans, Kimpton Hotels \& Restaurants, Marriott, Whole Foods Market, and Hyatt.

\section{Case 1: Wegmans}

Here is an example of a Wegmans employee wellness program from one Wegmans employee (Berman, 2013). Mark Novelli got a warning from a Wegmans nutritionist after finding out his blood pressure was at 180/120. Thanks to the free monthly screenings offered by his company, Mark realized the importance of changing his unhealthy lifestyle and lost 35 pounds in a month. Several years ago, Wegmans started to launch wellness programs to help its workers stay healthy 
and fit, which included blood pressure and nutrition coaching as well as on-site yoga and Zumba classes. Though these perks are common for tech giants like Google to attract engineering talent, Wegmans stands out for providing such wellness programs to a more diverse workforce. All employees from executives to checkout cashiers have access to health advice and fitness programs. According to the CEO of Wegmans (Berman, 2013), the company's efforts on employee wellness are aimed at the bottom line in addition to corporate social responsibility. Poor health among employees can have negative effects on businesses and cost companies more than half a trillion dollars. From 2008 to 2013, the percentage of Wegmans workers with high blood pressure dropped from 24 percent to 14 percent. Employee health screenings and fitness classes can be considered an extension of the same healthy-living value the company expresses to the public. Pacino, an IT worker at Wegmans, joined a $5 \mathrm{~K}$ training group offered through the company and dropped 50 pounds in two years. Also, she uses Wegmans' at-work yoga classes (see Exhibit 7) to get an hour of just me time every week to lessen the pressure. She said that she felt more energetic and that the wellness programs helped her perform the job better.

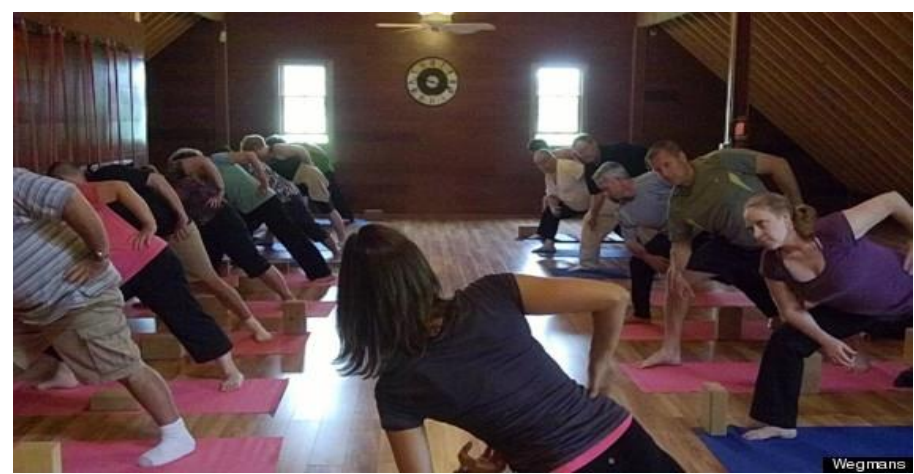

Exhibit 7. Wegman's staffs are doing Yoga class

\section{Case 2: Kimpton Hotels \& Restaurants}

Kimpton has approximately 8,100 employees in the United States. According to Kimpton (Fortune, 2015), almost 95 percent of its employees feel trusted towards the company and are willing to deliver caring, personal service to guests because of the great perks. The company also provides $\$ 1,500$ of college tuition reimbursement for all its staff. Besides classes related to work, classes such as stress management, positive employee relations, personal financial management, and English as a second language are all options for the workers. Kimpton has surprised housekeeping staff who work on hot days with boxes of personalized snacks or ice cream treats. Kimpton also rewards loyal staff with gifts or gift cards. Moreover, the staff can invite their family members or friends to have dinner at Kimpton's restaurants. Kimpton grants employees three days of paid sick leave. If staff' have a family member with a serious health condition, they can take 12 to 16 weeks of unpaid time during which their job and benefits are protected. Employees have access to insurance not only for themselves but also for their pets. Knowing that it is depressing to lose a pet, the company offers paid leaves for staff to give them time to recover (Great Places to Work, 2015). Kimpton partners with the Trevor Project, the leading national organization that provides services to lesbian, gay, bisexual, transgender, and questioning young people (Great Places to Work, 2015). The company encourages its employees to participate in social media and marketing campaigns as volunteers with the Trevor Project. Kimpton offers tax-preparation services to employees in Miami. Learning from high-tech companies, Kimpton 
schedules exercise elements such as yoga or organized walks into the agenda of every employee meeting (Great Places to Work, 2015). All hotels and restaurants have healthy snacks on hand for employees, which is similar to the high-tech companies as well. Also, employees can get a membership at a local gym with a company discount and can apply to be reimbursed for wellness activities such as smoking-cessation hypnosis. Another creative employee wellness program is called Kimpton Moments Chips (Toporek, 2015). If an employee offers superior care or service to customers and is witnessed by a co-worker, supervisor, or patron, he or she will receive a token. These tokens can be redeemed for prizes such as trips, TVs, iPods, and more.

\section{Case 3: Whole Foods Market}

Whole Foods combats high healthcare costs through innovative healthcare and wellness plans as well. One of them is called the Healthy Discount Incentive Program (Mackey, 2013). Based on degree of wellness, the company offers employees up to 20 percent in additional store discounts. The extra discount depends on the levels of cholesterol, height-to-waist ratio, and blood pressure, along with being nicotine free. On the other hand, Whole Foods offers a medically-supervised program to its unhealthiest team members who are overweight or have heart disease or diabetes. In the program, they receive intensive training to eat and live healthily. According to the company, team members often see so much progress within the first seven days that they realize they can control their health for the rest of their lives. Through these employee wellness programs, Whole Foods not only lowers its costs but transforms lives.

\section{Case 4: Marriott}

The National Business Group on Health announced Marriott as the winner of the 2015 Best Employers for Healthy Lifestyles awards (Marriott, 2015a). Marriott was the only winner from the hospitality industry. In 2010, Marriott launched a program called TakeCare Wellbeing to create a healthy working environment for its employees. The company offers stress management, exercise and fitness, nutrition and weight management, smoking cessation, and financial wellbeing services to their staff. According to David Rodriguez, the Global Chief Human Resource Officer at Marriott, "Taking care of our associates has been a vital part of the culture at Marriott since its founding in 1927" (Marriott, 2015b, para. 3). Last year, Marriott established a Healthy Hotel Certification program (see Exhibit 8) to publicly recognize hotels for creating a healthy work environment for their associates.

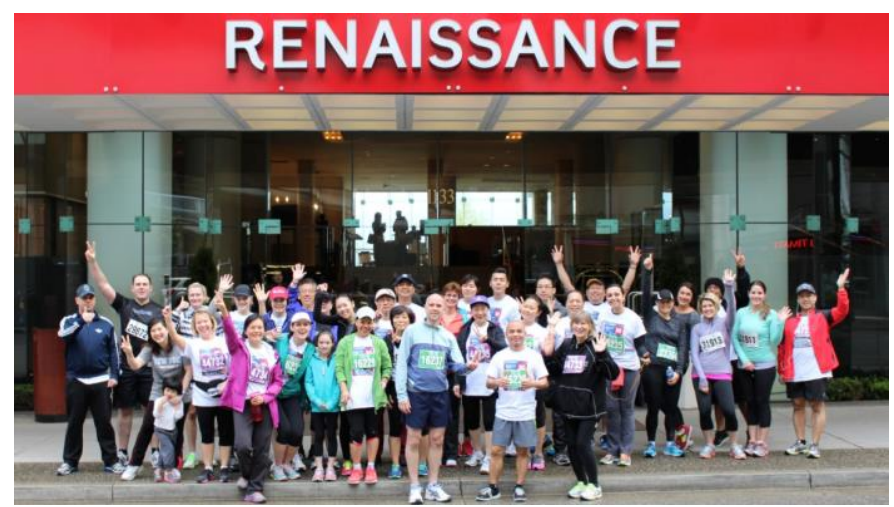

Exhibit 8. Over 100 Marriott hotels in the U.S., U.S.V.I. and Canada that achieved the TakeCare Healthy Hotel Certification for 2014. 
According to Rakesh Sarna, the group president for Hyatt (Martin, 2014), the company is now focusing on connecting guests with employees at a deeper, emotional level. The company tries to elevate the personal potential of hotel employees and their passion for offering service to the customers. Based on a model from the Institute of Design at Stanford, Hyatt developed training to teach its employees how to listen deeply to understand the emotion and the real need behind what guests say. To encourage employees to be creative when they serve customers and to make a positive impact on the customers' hotel experience, Hyatt honors the most creative teams with the Hyatt's CEO's Award for Innovation. Also, as a member of the Hyatt family, they can have complimentary and discounted stays at Hyatt hotels around the world. During work hours, they can have free meals in associate dining rooms. Fitness activities like Zumba classes and kickboxing are included in the wellness programs to help employees and their families stay healthy. Like Kimpton hotels, the staff have flexible work schedules in addition to paid holidays and vacation.

\section{Case 6: Westin}

Westin realizes the importance of the overall well-being of their staff. The company offers preand post-shift stretching wellness programs. Housekeepers often suffer from muscular soreness, so Westin provides specially designed New Balance shoes with arch support and shock absorption to its housekeeping staff (Westin, 2011). Also, employee cafeterias feature healthy menu items featuring Superfoods (food items that contain high amounts of antioxidants, polyphenols, vitamins, and minerals.) (Health, 2015). Many scientists believe that eating superfoods can reduce the risk of chronic disease and prolong life. Air quality is also an important factor that can affect the body and mind wellness. To improve the air quality in its working environment, Westin launched the Breathe program. Each Westin property introduces new ways such as smoke-free policies to provide healthier environments for guests and hotel staff (Westin, 2015).

\section{Case 7: Qdoba}

The working environment at most restaurant chains is very different from the typical corporate environment as well. Restaurants can meet obstacles when they apply wellness programs. For example, there may be a budget limit for on-site programs because restaurants may not have many employees. Qdoba Mexican Grill is one of the restaurant leaders that puts emphasis on employees' well-being. According to Restaurant Business Staff (2012), the company provides financial incentives to encourage employees to live a healthy lifestyle. Staff take part in biometric screening procedures that measure their tobacco habits and report cholesterol levels, which can earn them up to $\$ 520$ per year. Moreover, if an employee's spouse or domestic partner completes the biometric screening, the entire team can earn $\$ 1,040$. Additionally, employees can participate in a program that tracks physical activity and earn rewards up to $\$ 400$ per year. Qdoba's owners believe that the positive well-being of team members will help prevent potential healthcare issues, reduce absenteeism, and help control rising healthcare costs. To support the wellness program, the company has created an online portal to guide staff through enrollment and send email reminders. 


\section{Case 8: Noodles \& Company}

Noodles \& Company incentivizes biometric screening among employees, like Qdoba. Also, all employees of Noodles \& Company around the world have the freedom to choose how to pursue greater wellness. As Restaurant Business Staff (2012) reports, each employee gets balance bucks every six months to spend on anything such as a gym membership or new running shoes. Though, in the short-term, wellness programs raise the company cost, they can make a significant difference to the bottom line over time. However, according to Noodles \& Company, employers should not focus on the immediate benefits. Having a healthy work-life balance creates a better, more supportive culture, which also leads to improved productivity in the end.

\section{Conclusions}

Based on the cases above, I discovered that most hospitality companies that were listed in the Great Places to work for survey applied the innovative employee benefits typical of high-tech companies (Table 2).

Table 2. The Comparison of Wellness Programs From Companies

\begin{tabular}{lccc}
\hline Wellness program & Traditional hospitality company & $\begin{array}{c}\text { company } \\
\text { great place to work hospitality company }\end{array}$ & High-tech company \\
\hline Healthcare/medical benefits & $\sqrt{ }$ & $\sqrt{ }$ & $\sqrt{ }$ \\
Stress management & $X$ & $\sqrt{ }$ & $\sqrt{ }$ \\
Family-friendly benefits & $X$ & $\sqrt{ }$ & $\sqrt{ }$ \\
Healthy lifestyle incentives & $X$ & $\sqrt{ }$ & $\sqrt{ }$ \\
Flexible schedule & $X$ & $\sqrt{ }$ & $\sqrt{ }$ \\
Working environment & $X$ & $\sqrt{ }$ \\
Other & $X$ & & \\
\hline
\end{tabular}

The combination of traditional perks with technology and networking can lead to higher job satisfaction. As Miesen (2013) stated, "wellness programs are an umbrella term for a wide variety of initiatives - from paying for smoking cessation, to smartphone apps to track how much you walk or how well you comply with your plan of care, and everything in between" (para. 3). Hospitality company owners should think about offering immediate rewards when their staff participate in health initiatives such as weight loss or walking steps competition. Jawbone UP and Nike FuelBand are very popular among managers to motivate their staff. According to a study (Chapman, Colby, Convery, \& Coups, 2015), people with pedometers take 2,491 more steps every day.

Using new technology turns walking into a game that can lead employees to get more exercise. Also, people tend to care more about immediate and current incentives than future incentives. Instant feedback towards healthy behavior will make wellness programs work better. To get more employees engaged in these programs, companies should also make use of their social connection. Hospitality companies can reward staff who share their companies' creative benefits online and through social media. On the one hand, sharing may motivate more co-workers to participate. On the other hand, the companies will be regarded as cool places to work by the public. Also, taking care of employees' family members makes employees feel respect and trust from their companies (Skaria, 2016), which makes them concentrate more on their work and cater to guests with superior quality. From an economical perspective, for every dollar spent on wellness programs, companies make back \$3.27 on average (Baicker, Cutler, \& Song, 2010). Gallup confirmed the relationship between employee feelings and company outcomes. 
According to the study (Amabile \& Kramer, 2012), lost productivity from employee disengagement can be worth more than $\$ 300$ billion in the US every year. Another study (Harter, 2016) also found that business unit sales can be predicted by employees' feelings about the corporation. It is worth it for hospitality companies to invest in the innovation of their wellness programs. Ultimately, such programs keep workers from switching companies.

\section{Limitations and Future Research Directions}

Given the nature of the study, many cases are discussed and presented to reveal the success and effectiveness of employee wellness programs in the workplace. Limitations are observed and suggestions for future research are discussed. First, this study adopted a case study approach, which lacks quantitative validation and examination. Future research is advised to conduct field examination and quantitative analysis to demonstrate empirically the effectiveness of wellness programs in hospitality enterprises. Second, this study only reviewed the wellness programs practiced by high-tech companies and some of the top hospitality companies. A broader scope of business review should be undertaken to present a more comprehensive overview of wellness practices in the current market. Third, there is a strong link proclaimed between effective employee wellness programs and employee-related positive outcomes; however, few studies have ever established the empirical support for this statement. Therefore, it is suggested that future research should investigate the impacts of employee wellness programs on employee outcomes to quantify the benefits of successful wellness programs.

\section{References}

Abdel-Moty, K. (2010). Creating a wellness program for hotel front desk employees. Retrieved from https://digitalscholarship.unlv.edu/cgi/viewcontent.cgi?article=1476\&context=thesesdissertations

Amabile, T., \& Kramer, S. (2012). Employee happiness matters more than you think. Retrieved from https://www.london.edu/faculty-and-research/lbsr/employee-happiness-matters-more-than-you-think

Anderko, L., Roffenbender, J. S., Goetzel, R. Z., Millard, F., Wildenhaus, K., DeSantis, C., \& Novelli, W. (2012). Promoting prevention through the affordable care act: Workplace wellness. Preventing Chronic Disease, 9(12), 1-5. doi.org/10.5888/pcd9.120092

Baicker, K., Cutler, D., \& Song, Z. (2010). Workplace wellness programs can generate savings. Health Affairs, 29(2), 304-311.

Bakker, A., Schaufeli, W., Leiter, M., \& Taris, T. (2008). Work engagement: An emerging concept in occupational health psychology. Work \& Stress, 22(3), 187-200.

Berman, J. (2013). Wegmans improves its bottom line by helping employees shrink their waistlines. Retrieved from http://www.huffingtonpost.com/2013/08/05/wegmans-wellness_n_3696411.html

Blachowicz, E., \& Letizia, M. (2006). The challenges of shift work. Medsurg Nursing, 15(5), 274-280.

Borenstein, L. (2015). Employee wellness programs are due for an overhaul. Retrieved from http://www.entrepreneur.com/article/244040

Boyle, E., \& Harter, J. (2014). Why your workplace wellness program isn't working. Retrieved from https:/www.gallup.com/workplace/236531/why-workplace-wellness-program-isn-working.aspx

Bureau of Labor Statistics. (2010). Lodging managers. Retrieved from https://www.bls.gov/ooh/management/lodging-managers.htm

Byrne, D. W., Goetzel, R. Z., McGown, P. W., Holmes, M. C., Beckowski, M. S., Tabrizi, M. J., \& Yarbrough, M. I. (2011). Seven-year trends in employee health habits from a comprehensive workplace wellness program at Vanderbilt University. Journal of Occupational and Environmental Medicine, 53(12), 1372-1381.

Chapman, G. B., Colby, H., Convery, K., \& Coups, E. J. (2015). Medical goals and social comparisons promote walking behavior. Medical Decision Making, 36(4), 472-478.

Eadicicco, L. (2015). The amazing perks of working at Apple. Retrieved from https://www.businessinsider.com/best-things-about-working-at-apple-2015-2 
Fortune. (2015). 100 best companies to work for $\mid 2015$ - Ranking the brands. Retrieved from: http://www.rankingthebrands.com/The-Brand-Rankings.aspx?rankingID=100\&year=9

Fujioka, C. (2008). Japanese firm offers heartache leave for staff. Retrieved from http://www.reuters.com/article/2008/01/28/us-japan-leave-idUST8913820080128

Gallup-Sharecare Well-Being Index. (2015). Retrieved from https://wellbeingindex.sharecare.com/

Garun, N. (2012). Evernote employees enjoy paid unlimited vacation, laser-shooting robots, and housekeeping. Retrieved from https://www.digitaltrends.com/home/evernote-employees-enjoy-paid-unlimited-vacationlaser-shooting-robots-and-housekeeping/

Goetzel, R. Z., \& Ozminkowski, R. J. (2008). The health and cost benefits of work site health-promotion programs. The Annual Review of Public Health, 29, 303-323.

Great Place to Work. (2015). Kimpton Hotels \& Restaurants. Retrieved from http://reviews.greatplacetowork.com/kimpton-hotels-restaurants

Hakanen, J. (2006). Burnout and work engagement among teachers. Journal of School Psychology, 43(6), 495-513.

Harter, J. (2016). Moneyball for business: Employee engagement meta-analysis. Retrieved from https://www.gallup.com/workplace/236468/moneyball-business-employee-engagement-meta-analysis.aspx.

Harter, J. K., Schmidt, F. L., \& Keyes, C. L. (2003). Well-being in the workplace and its relationship to business outcomes: A review of the Gallup studies. Flourishing: Positive Psychology and the Life Well-Lived, 2, 205-224.

Health Fitness Revolution. (2015) Top 10 fittest fortune 100 companies to work for. Retrieved from http://www.healthfitnessrevolution.com/top-10-fittest-fortune-100-companies-work

Health. (2015). Superfoods you need now. Retrieved from http://www.health.com/health/gallery/0,20306775,00.html

Hochart, C., \& Lang, M. (2011). Impact of a comprehensive worksite wellness program on health risk, utilization, and health care costs. Population Health Management, 14(3), 111-116.

Huddleston, T. (2014). Tech companies are hiring 'perks managers' in a fight to woo talent. Retrieved from http://fortune.com/2014/11/21/tech-industry-perks-managers

Intel. (2015). Work life balance. Retrieved from http://www.intel.com/content/www/us/en/jobs/life-at-intel/usa/lifeand-work.html

Kaplan, R. M., \& Stone, A. A. (2013). Bringing the laboratory and clinic to the community: Mobile technologies for wellness and disease prevention. Annual Review of Psychology, 64, 471-498.

Lee, J., \& Pati, N. (2012). New insights on the operational links between corporate sustainability and firm performance in service industries. International Journal of Business Insights \& Transformation, 4(3), 8093.

Lefebvre, R. C., \& Flora, J. A. (1988). Social marketing and public health intervention. Health Education \& Behavior, 15(3), 299-315.

Line, N. D., \& Runyan, R. C. (2012). Hospitality marketing research: Recent trends and future directions. International Journal of Hospitality Management, 31(2), 477-488.

Mackey, J. (2013). How whole foods market innovates in employee health care. Harvard Business Review. Retrieved from https://hbr.org/2013/01/how-whole-foods-market-innovat

Marriott. (2015a). Marriott international recognized for outstanding work-life. Retrieved from: http://news.marriott.com/2015/02/marriott-international-recognized-for-outstanding-work-life-programs/

Marriott. (2015b). Marriott news center: Workplace. Retrieved from http://news.marriott.com/2015/06/marriottrecognized-for-healthy-workplace-environment/.

Martin, S. (2014). Hyatt named to the 2014 fortune 100 best companies to work. Retrieved from http://www.businesswire.com/news/home/20140116006496/en/Hyatt-Named-2014-Fortune

Messieh, N. (2012). 12 startups that offer their employees the coolest perks. Retrieved from https://thenextweb.com/insider/2012/04/09/12-startups-that-offer-their-employees-the-coolest-perks/

Miesen, M. (2013). Wellness programs aren't working: Three ideas that could help. Retrieved from http://thehealthcareblog.com/blog/2013/04/01/wellness-programs-arent-working-three-ideas-that-couldhelp/

Ministry of Manpower. (2003). Occupational safety and health guidelines for the hotel industry. Retrieved from https://www.scribd.com/document/289378381/Guidelines-for-the-Hotel-Industry.

Mistry, K. B., Minkovitz, C. S., Riley, A. W., Johnson, S. B., Grason, H. A., Dubay, L. C., \& Guyer, B. (2012). A new framework for childhood wellness: The role of policies and programs in building capacity and foundations of early childhood health. American journal of public health, 102(9), 1688-1696. 
Oscar, R. (2014). Mobile communication tools maximize the benefits of high-deductible health plans. Managed Care Outlook, 27(11), 1-6.

Paul, M. (2014). New sitting risk: Disability after 60. Retrieved from https://news.northwestern.edu/stories/2014/02/new-sitting-risk-disability-after-60

Pronk, N. (2014). Best practice design principles of worksite health and wellness programs. ACSM's Health \& Fitness Journal, 18(1), 42-46.

Restaurant Business Staff. (2012). Set up a wellness program for restaurant employees. Retrieved from https://www.restaurantbusinessonline.com/set-wellness-program-restaurant-employees

Rooney, B. (2014). Facebook, Apple pay to freeze employees' eggs. Retrieved from http://money.cnn.com/2014/10/14/news/companies/facebook-apple-egg-freeze/

SHRM. (2015). 2015 employee job satisfaction and engagement. Retrieved from https://www.shrm.org/hrtoday/trends-and-forecasting/research-and-surveys/pages/job-satisfaction-and-engagement-reportoptimizing-organizational-culture-for-success.aspx

Skaria, S. (2016). What's more valuable: Skills or passion? Retrieved from https://www.linkedin.com/pulse/whatsmore-valuable-skills-passion-saju-skaria

Stellman, J. M. (1999). Women workers: The social construction of a special population. Occupational Medicine, 14(3), 559-580.

Toporek, A. (2015). 5 Ways Kimpton builds great customer experiences. Retrieved from http://360connext.com/5ways-kimpton-builds-great-customer-experiences/

Wang, C. J., Tsai, H. T., \& Tsai, M. T. (2014). Linking transformational leadership and employee creativity in the hospitality industry: The influences of creative role identity, creative self-efficacy, and job complexity. Tourism Management, 40, 79-89.

Westin. (2011). Westin employers and employees benefit from wellness programs. Retrieved from http://news.cision.com/westin-hotels---resorts/r/westin-employers-and-employees-benefit-from-wellnessprograms-during-tough-economic-times,c9198898

Westin. (2015). Smoke free Westin Hotels and guest rooms. Retrieved from https://www.businesswire.com/news/home/20051205005462/en/Westin-Hotels-Resorts-Smoke-FreeWestin-Hotels-100

Xanthopoulou, D., Bakker, A. B., Demerouti, E., \& Schaufeli, W. B. (2009a). Reciprocal relationships between job resources, personal resources, and work engagement. Journal of Vocational Behavior, 74(3), 235-244.

Xanthopoulou, D., Bakker, A. B., Demerouti, E., \& Schaufeli, W. B. (2009b). Work engagement and financial returns: A diary study on the role of job and personal resources. Journal of Occupational and Organizational Psychology, 82, 183-200. 